\title{
Hirschmanian Themes of Social Learning and Change
}

\author{
David Ellerman (DECVP) \\ World Bank*
}

\begin{abstract}
The purpose of this paper is to map today's debate about the effectiveness of conditionalities and adjustment lending back into the older balanced versus unbalanced growth debate. A 'Christmas tree' of conditionalities on an adjustment loan is in general ineffective in developing 'ownership' or in generating sustainable change. Development agencies need to select for genuine commitment to policy reforms on the part of client governments rather than think that such commitments can be 'bought' with aid. This raises the question of "How does a country get from here to there?" and this is where the Hirschmanian notion of unbalanced growth can be 'rediscovered.' A country that has already developed a "good policy environment" and can implement a 'Christmas tree' of conditionalities is like a country that can implement the "balanced growth plans" of the earlier debate. Such a country would be well on its way to development. When the central government lacks this capability, the Hirschmanian approach is to look for "hidden rationalities" in the small or in the periphery, and then to help the small beginnings to spread using, where possible, the natural pressures of linkages. Rather than trying to put all the pieces of a puzzle together at once to make it look like the picture on the box, one starts in the small where the pieces are starting to fit together and then builds outward using the linkages between the pieces. Similar results from a number of authors are used to help "triangulate" the basic ideas.
\end{abstract}

\footnotetext{
* The findings, interpretations, and conclusions expressed in this paper are entirely those of the author and should not be attributed in any manner to the World Bank, to its affiliated organizations, or to the members of its Board of Directors or the countries they represent. This paper grew in part out of discussions with Vladimir Kreacic (ECCUA) to try to theoretically understand the relative success of his Bank project PSD I/II in Moldova.
} 


\section{Table of Contents}

Introduction

Conditionality-Based Reforms as Another Failure of Development Planning

Doubts about Conditionalities

Reframing the Question about Conditionalities

Hirschman's Theory of Unbalanced Growth: "One Thing Leads to Another"

Other Theories of Decentralized Social Learning and Change

Herbert Simon's Theory of Bounded Rationality

Charles Lindblom's Theory of Incrementalism and Muddling-Through

Donald Schön's Theory of Decentralized Social Learning

Everett Roger's Theory of Decentralized Innovation and Diffusion

Just-in-Time Inventory and Continuous Improvement Systems

Charles Sabel's Theory of Learning by Monitoring

Could a Project be a Decentralized Competitive Social Learning Process?

Conclusions

References 


\section{Introduction}

While "central planning" is now held in ill-repute, similar social engineering techniques are still promoted in a number of different guises. Indeed, the basic default model of central government-imposed reforms and change, often backed by conditionalities imposed by aid agencies, suffers from many of the same problems as central planning. Ironically as countries moved away from centralized planning to the decentralized system of economy known as the "market," they still cling to centralized models of social learning, policy reform, and institutional change. Yet the virtues of systems of decentralized initiatives with centralized regulation are broader than just market activities-which Hayek considered more broadly as a spontaneous process of forming order through mutual adjustment and the use of local knowledge for problem solving. ${ }^{1}$ I will focus on a broader range of decentralized systems (still with some centralized regulation, coordination, and facilitation) that address some problems of development.

One of the oldest and strongest challenges to the planning approach to development comes from the seminal work of Albert Hirschman. He responded to the balanced growth, big push, and development planning models with an alternative framework of "unbalanced growth." The limited powers of cognition and implementation of central authorities in the face of the complexity of organizational, institutional, and social realities do not give much hope for social engineering approaches-even if the latter did not also contradict the normative goals of development as the exercise of freedom and autonomy [Sen 1999]. Hirschman as a keen observer of the development process saw successes as taking place in a rather different way and he recommended that development projects attend to those "hidden rationalities" more that the dreams of technocratic rationality entertained by social engineers. Projects need to awaken and enlist local energies and knowledge for trial-and-error problem solving. But each problem solved brings to the foreground other problems and opportunities (forward and backward linkages). Change unfolds because "one thing leads to another"-not because a given rational plan can be implemented step by step.

Consider the analogy with the way an entrepreneur might develop a business. Success in an initial effort will create bottlenecks and pressures upstream or downstream that need to be resolved-as well as opportunities that can be captured. One thing leads to another in an evolutionary process of groping, adaptive learning, and experimentation. Each step is driven by the local needs to relieve pressures or grab opportunities. It is rather different from following the imposed performance incentives to move step by step through an engineering plan to construct a building or build a bridge. By studying the successful development of a complex multi-faceted business, would-be entrepreneurs might gain much insight into the process but they should beware of thinking that the entrepreneurial process can be reduced to a checklist, business plan, or blueprint.

If entrepreneurial business development is too fraught with uncertainties, complexities, instabilities, and incomplete knowledge to submit to technocratic planning, then one might well expect the same to hold for the processes of social reform, change, and development. For those

\footnotetext{
${ }^{1}$ For example, see "Competition as a Discovery Procedure" in Hayek 1978. Michael Polanyi 1951 finds a similar process of mutual adjustment in the progress of science. See Lavoie 1985 and 1992 on Hayek, Polanyi, and later developments.
} 
broader processes, Hirschman referred to the "entrepreneurs" as reformmongers and described that vision of growth and development as "unbalanced growth."

Learning, experimentation, and a one-size-does-not-fit-all pragmatism are basic to any alternative to the planning, command, and controls models of development. A number of related theories developed in recent decades will also be surveyed:

- Herbert Simon's notion of bounded rationality and its multifarious implications,

- Charles Lindblom's theory of incrementalism and muddling-through,

- Donald Schön's theory of decentralized social learning,

- Everett Roger's model of decentralized innovation and diffusion,

- Japanese management techniques of just-in-time inventories, local problem solving, benchmarking, and continuous improvement, and

- Charles Sabel's theory of learning by monitoring.

Finally some half-baked ideas will be broached for designing decentralized programs for the World Bank or other development agencies.

\section{Conditionality-Based Reforms as Another Failure of Development Planning}

\section{Doubts about Conditionalities}

Conditionalities on development loans or donor grants are much like the plan specifications in a model of centrally planned and socially engineered reforms. In the literature on aid for economic development, a substantial body of research now questions the effectiveness of conditionalities in policy-based lending such as structural adjustment loans (SALs). ${ }^{2}$ The doubts apply less to the "pro forma," "stroke-of-the-pen," or price-based conditionalities than to those aimed at institutional reforms. As in Killick et al. 1998, our concern is with "hard-core" conditionalities, i.e., conditions attached to credits or aid that are intended to induce policy-based institutional reforms in a country.

Institutional reforms lie at the opposite end of the simplicity-complexity spectrum by comparison with currency devaluations: they are not for the most part amenable to treatment as preconditions; donor agencies are liable to have difficulties in keeping track of the extent of compliance; and such reforms are often imperfectly under the control of the central authorities, take time, typically involve a number of agencies and are liable to encounter opposition from wellentrenched beneficiaries of the status quo. [Killick et al. 1998, 40]

In the face of these doubts, what is to be done?

Some practitioners plod onward thinking that they only need to make conditionalities fewer, "tougher" and more "performance-based." Such practices do little to address some of the basic reasons for the ineffectiveness. Tougher performance-based conditionalities do not solve the basic motivational problem. This may seem strange from the narrow economic viewpoint, e.g.,

${ }^{2}$ See the discussion and references in Mosley et al. 1991, World Bank 1998, and Killick et al. 1998. 
agency theory. Doesn't the carrot of aid provide the motivation? In psychological terms, the problem is that the aid only provides extrinsic motivation. Real reforms beyond the stroke-ofthe-pen variety will usually require some own-reasons or more intrinsic motivations for successful implementation. Otherwise there is only the motivation to make the minimal outward changes to get the aid. In addition, there is a negative reactance against the attempt to externally impose changes. Making conditionalities "tougher and more performance-based" does not even attempt to address these underlying motivational problems. Imposed reforms based on conditionalities share many of the flaws of older development planning strategies.

Another approach to the doubts about aid-baited conditionalities is to emphasize that aid works best in countries that have good policies and that aid is largely wasted in countries with poor policies. In light of the doubts about conditionalities turning around poor policies, it is suggested that good policy environments should be selected for more aid. This approach more finesses the problem than solves it. The problem is the social learning process to get a country from poor policies to better policies.

This approach falls back on the one big ex ante conditionality of "good policies" plus policy dialogue and knowledge-without-aid. This one-big-carrot approach has the same if not worse motivational problems as the many-small-carrots approach. Moreover it is doubtful that it would be sustained under real world conditions of partial fulfillment. If the list of good policies was partly but not completely fulfilled, then strong political and disbursement pressures would build (from both sides) to give at least "half a carrot" and we are in effect back to the many-smallcarrots approach.

Aid agencies have their preconceptions of "virtue" in the sense of good policies. They try to "buy virtue" by imposing conditionalities on program aid geared to "virtuous behavior" defined by various outward acts of allegiance to and implementation of "good policies." But virtue can only be found and selected, not bought. ${ }^{3}$ If we take "virtue" as being defined not just by behavior but also by the right internal motives, then aid can only buy a faux-virtue. Such aid pushes the external motive of receiving the aid into the motivational foreground and thus establishes external control-the lack of autonomy.

Autonomy-compatible aid would remove impediments and thus enable "virtuous action" where the internal motive was already present and remains in the motivational foreground in accordance with the idea of finding out what people are already motivated to do and helping them do it better. ${ }^{4}$ "In these situations, the donor would set himself the task of rewarding virtue (or rather, what he considers as such) where virtue appears of its own accord." ${ }^{5}$ This leads straightaway to the "paradox" that aid is only autonomy-compatible when it does not do what is conventionally taken as a major purpose of program aid — to tip the balance of motives in favor of reforms and good policies.

\footnotetext{
3 See World Bank 1998.

4 " The first task is to study what people are already doing...and to help them do it better....

The second task is to study what people need and to investigate the possibility of helping them to cover more of their needs out of their own productive efforts." [Schumacher 1997, 125]

${ }^{5}$ Hirschman 1971, 204. Italics added.
} 
Paradoxically, therefore, program aid is fully effective only when it does not achieve anything - when, that is, no quid pro quo (in the sense of a policy that would not have been undertaken in the absence of aid) is exacted as the price of aid. [Hirschman 1971, 204]

Moreover, once it is known that "virtue" is being rewarded by the donor, then mimicry in the form of "virtuous behavior" may be elicited in order to also be rewarded-and that "virtue" does not appear "of its own accord." This supply effect of such externally motivated mimicry greatly complicates the provision of aid.

When an externally offered reward or punishment is used successfully to redirect a person's behavior, then the behavior is said to have an "external locus of causality." When one acts for one's own reasons and is the source of one's actions, then one would be said to have an "internal locus of causality." Having an internal locus of causality is to act autonomously in contrast to responding to heteronomously imposed rewards or punishments. ${ }^{6}$

External interventions by other people intended to change a person's behavior pose a threat to autonomy. The threat-to-autonomy or reactance [see Brehm 1972] effect results from using external motivators - carrots and sticks — to shift the locus of causality from internal to external. ${ }^{7}$ The effect shows itself in a poor quality and low effort performance, in sullen and perfunctory behavior fulfilling the letter but not the spirit of an agreement, and perhaps even in the urge to defiantly do the opposite just to show one's autonomy. ${ }^{8}$ Hirschman refers to these effects as the "hidden costs" [1971, 207] of program aid while Lepper and Greene [1978] call them the "hidden costs of rewards."

In the aid context, "good policies" bought by conditioned aid are usually ineffective. If the policies were not adopted by the government independently of the aid, then the policies would tend to be

adopted by aid-hungry governments in spite of continuing doubts of the policy makers themselves, resistance from some quarters within the government, onslaught against the "deal" from the opposition, and general distaste for the whole procedure.

Naturally, doubts and reservations are not voiced at the moment of the aid compact; hence the delusion on the part of the donor that there has been a full meeting of minds. But soon after virtue has been "bought" through aid under

\footnotetext{
${ }^{6}$ We use autonomy or internal causation broadly to include not only one's 'original' integrated sense of self but norms based on social interactions which are eventually integrated and internalized so following those norms would come to have an internal locus of causality. See Deci and Ryan 1985, Chapter 5.

7 For example, suppose one buys a townhouse in the middle of Winter and is looking forward to Spring to spruce up the poorly attended front yard. But the Townhouse Association Beautification Committee [a.k.a. "Lawn Nazis"] arrives before Spring to inform the new owners that they must attend to the yard or face certain penalties. Instead of just thinking "Now we have two reasons to spruce up the lawn," the new owners might well resent the attempt to externalize their locus of causality.

8 "Whatever task is not chosen of man's own free will, whatever constrains or even only guides him, does not become part of his nature. It remains forever alien to him; if he performs it, he does so not with true humane energy but with mere mechanical skill." [von Humboldt 1963, 47]
} 
these conditions, the reservations and resistances will find some expression-for example, through half-hearted implementation or sabotage of the agreed-to policies - and relations between donor and recipient will promptly deteriorate as a result. [Hirschman 1971, 205]

\section{Reframing the Question about Conditionalities}

The debate about conditionalities is to some extent ill-posed. In 'psychological' terms, the question is how to best indirectly foster the country's intrinsic motivation for reforms as opposed to the agency theory question of how to best impose carrots and sticks (extrinsic motivation) to promote reforms. Where are the possible reforms that have some rootedness or embeddedness in the country and are not in response to an offer of assistance? The best way to assure that a reform project has some "intrinsic motivation" or rootedness is not to start a project but to find it. ${ }^{9}$

I began to look for elements and processes...that did work, perhaps in roundabout and unappreciated fashion. [T] his search for possible hidden rationalities was to give an underlying unity to my work. ...[T] he hidden rationalities I was after were precisely and principally processes of growth and change already under way in the societies I studied, processes that were often unnoticed by the actors immediately involved, as well as by foreign experts and advisors. [Hirschman 1984, 91-3]

With this reframing, the conditionality debate joins an older debate between balanced and 'unbalanced' notions of growth.

\section{Hirschman's Theory of Unbalanced Growth: "One Thing Leads to Another"}

From the earliest postwar discussions of growth, it seemed clear that developing countries were caught in many vicious circles of poverty and that coordinated actions along a broad front-a big push-might be necessary to exploit the many mutually supporting complementarities and to thus escape the low-level trap. ${ }^{10}$ Formal growth models emphasized the efficiency properties of balanced growth paths and development planning models also reinforced the mental image of coordinated action across sectors. ${ }^{11}$ All of these fell into the general category of balanced growth models.

All the balanced growth models suffered from the same problem of in effect assuming that which needed to be developed. A country with the wherewithal to carry out a coordinated 'big push' of across-the-board developmental actions would already be well on its way to development (particularly in terms of capability), not languishing in a low-level poverty trap. These models also made the more subtle but equally if not more dubious assumption that all the relevant agents in a country would simultaneously undergo the required social learning and transformations of habits that would be required for the big push to succeed (as if a school of fish would altogether

\footnotetext{
9 Note the contrast with the project manager who wants to show his boss that he "made a difference" by "starting" a project.

10 See Rosenstein-Rodan 1943.

11 See Solow 1956; Rosenstein-Rodan 1964.
} 
decide to jump out of the water and become a new species of amphibians). It is as if one could put the pieces of a jigsaw puzzle together all at once after being told to do it like the picture on the box (e.g., fulfill the 'Christmas tree' of conditionalities on a structural adjustment loan). That is not how social learning and change tends to take place.

One of the few voices dissenting from the then near-litany of balanced growth, big push, and national planning models was that of Albert O. Hirschman ${ }^{12}$ who noted that "if a country were ready to apply the doctrine of balanced growth, then it would not be underdeveloped in the first place." [1961 (1958), 53-4] In terms of the conditionalities debate, if a country could fulfill the typical "Christmas tree" of conditionalities attached to multilateral lending (or the one big goodpolicies screen), then it would not be in a low-level developmental trap in the first place.

In contrast to the balanced growth approach, Hirschman develops a theory of unbalanced growth which might usefully be viewed as a theory of social learning and social change. ${ }^{13}$ In the 1961 preface to the paperback edition of The Strategy of Economic Development, Hirschman restates the essential point of the theory.

True, automotive vehicles are not much good without highways and modern highways are rather useless without vehicles. But this does not mean that the only or even the best way in which we can develop our transportation system is by expanding simultaneously and evenly both the automotive industry and the highway network. Why not take advantage of the stimulus that is set up by expansion of the one toward that of the other? In other words, I do not deny by any means the interrelatedness of various economic activities of which the balanced growth theory has made so much. On the contrary, I propose that we take advantage of it, that we probe into the structure that is holding together these interrelated activities. As in the atom, there is much energy here that can be and is in fact being utilized in building up economic development nuclei. Later on these nuclei look as though they could never have been separated even for a single instant when in actual fact they might never have been assembled had not a sequential solution, i.e., an unbalanced growth sequence been found, by accident, instinct, or reasoned design. To look at unbalanced growth means, in other words, to look at the dynamics of the development process in the small. But perhaps it is high time that we did just that. [Hirschman 1961, viii-ix]

The emphasis on the "dynamics of the development process in the small" has not been well received by university economists devising formal macroeconomic models of growth. ${ }^{14}$

\footnotetext{
12 The locus classicus is his 1958 The Strategy of Economic Development but see also Streeten 1959 as well as a few of Hirschman's typically self-subverting caveats in chapter 3 of A Propensity to Self-Subversion [1995].

13 See for instance Schön 1994.

14 "In effect, Hirschman said that both the theorist and the practical policymaker could and should ignore the pressures to produce buttoned-down, mathematically consistent analyses and adopt instead a sort of muscular pragmatism in grappling with the problem of development. Along with some others, notably Gunnar Myrdal, Hirschman did not wait for intellectual exile: he proudly gathered up his followers and led them into the wilderness himself. Unfortunately, they perished there." [Krugman 1994, 40]
} 
Learning and change is driven by problem-solving. Not all problems can be attacked at once so attention and aid is first focused in the small on the sectors or localities where some of the preconditions are in place and where initiative is afoot on its own. The initial small successes will then create pressures through the forward and backward linkages to foster learning and change that is nearby in sectorial or locational terms-all of which might lead to a "growth pole"15 or local industrial district. Sometimes these projects might be initially in protected or "ringfenced" areas more isolated from the forces reinforcing the low level traps (e.g., corruption and a predatory government). The successes when broadcast horizontally to those facing similar problems will start to break down the paralyzing beliefs that "nothing can be done" and will thus fuel broader initiatives that take the early wins as their benchmark. ${ }^{16}$ Unlike a model that assumes large-scale organized social action directed by the government, the parties are responding to local pressures and inducements from their economic partners or to opportunities revealed by others in a similar position.

One thing leads to, induces, elicits, or entrains another thing through chains of "tensions, disproportions, and disequilibria." Hirschman at one point refers to the principle of unbalanced growth as "the idea of maximizing induced decisionmaking" [1994a, 278]. The problem-solving pressures induced by unbalanced growth will call forth otherwise unused resources and enlist otherwise untapped energies. As a project moves from one bottleneck and crisis to another (in comparison with the smooth planned allocation of resources in a project), then "resources and abilities that are hidden, scattered, or badly utilized" [1961, 5] will be mobilized. Hirschman [1984, 95] notes the connections with Cyert and March's notion of "organizational slack" [1963] based on Herbert Simon's theory of "satisficing" [1955], with Nathan Rosenberg's theory [1969] that technological innovation is strongly influenced by "inducing" or "focusing" events such as strikes and wars, and, above all, with Harvey Leibenstein's theory of X-inefficiency [1966, 1976]. Edmund Burke had captured part of the basic idea:

[Difficulty] has been the glory of the great masters in all the arts to confront, and to overcome; and when they had overcome the first difficulty, to turn it into an instrument for new conquests over new difficulties;... . He that wrestles with us strengthens our nerves, and sharpens our skill. Our antagonist is our helper. This amicable conflict with difficulty obliges us to an intimate acquaintance with our object, and compels us to consider it in all its relations. It will not suffer us to be superficial. [1937, 299-300]

In addition, there seems to be another angle to be considered in more depth below. Compare a natural activity that people carry out for their own reasons ("unbalanced growth") with a planned, check-listed, and choreographed version of the same activity (a balanced growth plan). The problem basic to organizational theory is to arrange work so that it is more like the former than the latter. This involves the contrast between intrinsic and extrinsic motivation, a theme

\footnotetext{
15 See Perroux 1953.

16 In some cases knowledge of others' successful models is necessary even for possible learners to formulate their own problems. "Managers don't know what they want until they see what they can get; in this sense, solutions are used to formulate problems." [Cole 1989, 36] This mutual influence of means and ends is characteristic of the attitude of pragmatism.
} 
developed elsewhere [Ellerman 2000a,b] concerning Douglas McGregor's "Theory Y." This will provide another set of arguments for what might be broadly taken as Hirschmanian strategies.

One can draw analogies to the process of individual learning. Suppose one takes a static snapshot of a person's beliefs before and after learning some new and complex interconnected subject matter. The older set of beliefs might have certain self-reinforcing properties. It might at first seem difficult to change one part of the set of beliefs since one would then have some cognitive dissonance with the remaining older beliefs. One could imagine simply changing all the beliefs at once to arrive at a new self-reinforcing set. But that is rarely how learning takes place. Against the forces of self-preservation of the "whole cloth" of older beliefs, there are the incentives to solve problems for which the old beliefs might be inadequate. Change might start in the small where problem-solving progress might be made by unraveling and changing some of the beliefs. But now the interconnections can help to unravel the older cloth. "Bottlenecks" or inconsistencies will appear between the old and new beliefs, and problem-solving pressures will be transmitted forwards, backwards, and sideways to adjust other beliefs. "One thing leads to another" and eventually the person will arrive at a new set of interconnected beliefs.

Now consider the viewpoint of the knowledgeable outsider, a "teacher" or "trainer," who understood all along the problem-solving superiority of the new set of beliefs. Why couldn't he just give a "core course" to impart the new knowledge to the student and thereby save the pupil all the time, energy, and pain of "learning the hard way"? ${ }^{17}$ Carrots and sticks, aid and conditionalities, could even incentivize the "learning process." While a veneer of some "knowledgeable behaviors" might be incentivized-particularly in "good students"-by such carrots and sticks, learning that transforms older beliefs does not take place in that manner. In order for learners to have an "ownership" of new knowledge and for the new knowledge to have a transformative effect, the knowledge must be more the fruits of the learner's own activities. Such knowledge comes out of a constructivist active learning process, not out of a pedagogy of the teaching imparting, transmitting, disseminating, or pouring new knowledge into passive students. With a constructivist pedagogy, the teacher is more a coach, guide, and midwife helping the learners in a more indirect manner to help themselves.

Hirschman uses the metaphor of a jigsaw puzzle for the set of problems facing a developing country [1961, 81-2]. One could imagine a rather superhuman act of putting all the pieces together at once to solve the puzzle. Indeed don't those who have seen and studied seemingly similar puzzles put together elsewhere have that knowledge? That is the comforting fantasy of those who promote comprehensive, integrated, and balanced reform programs. Do all these things together (so that it looks like the "picture on the puzzle box") and you will have solved your problems! But for the variety of reasons outlined above, countries cannot just solve all their problems at once. They must start with a few pieces that fit together and try to work outward to find other pieces that fit. Not all starting points are equal. Certain pieces of the puzzle may have nearby connections and linkages that allow building that part of the puzzle quickly-as opposed to parts whose solution might give little insight or impetus to solving the nearby parts. Perhaps someone who has seen similar puzzles solved would be a good coach to suggest promising starting points or fruitful directions for progress. No doubt it would be helpful to study the

${ }^{17}$ Hirschman notes that "such practices [will] tend to cut short that 'long confrontation between man and a situation' (Camus) so fruitful for the achievement of genuine progress in problem-solving." [1973, 240] 
"picture on the box." But the actual solving of the puzzle is a piecemeal process starting in one or more propitious places and working outward through fruitful linkages to finally arrive at the new overall configuration.

The Hirschmanian unbalanced growth approach to institutional change is an alternative to the planning approaches that try to "do everything at once" for fear that piecemeal attempts will fail (as they undoubtedly might). That is why it is important to choose the "pieces" of the piecemeal or incremental approach quite carefully.

A comprehensive attack on all the problems faced by an institution cannot hope to achieve "final" results in a specified time. Instead, a few aspects can be identified on which progress is feasible given the general operational level of the institution, and the program can concentrate on those aspects for a reasonable period, say, three years. After that, the progress that has been made will have ripple effects on other parts of the institution. At that point a new program can be designed that takes account of the new realities-including changes in personnel-but that focuses on another limited number of objectives. In sum, comprehensiveness in scope and in time should be abandoned in institutional development efforts, and a partial, cumulative, and highly focused approach pursued. [Israel 1987, 200]

Douglass North notes that "an essential part of development policy is the creation of polities that will create and enforce efficient property rights" but that "we know very little about how to create such polities." [North 1994, 366] Yet as these social learning processes develop largely on the basis of their own released energies, new demands will be made on the center or government to reform institutions, to provide infrastructure, and to clear away impediments, ${ }^{18}$ and that in turn will spur further progress on the ground.

There are many well-known public or semipublic goods of this sort, from power, transportation, and irrigation to education and public health. Often designated as "infrastructure," as though they were preconditions for the more directly productive activities, these goods have more usually been provided in response to urgent demands emanating from such activities and from their need for consolidation, greater profitability, and further expansion. [Hirschman 1981, 80$1]^{19}$

These induced demands for reforms are quite different from the externally imposed conditionalities that stipulate certain reforms or from reforms given by the benevolent "grace" of

\footnotetext{
${ }^{18}$ Hirschman quotes approvingly a consulting engineer who suggests a road surface that would better elicit pressure for maintenance on the public works authorities. "We assumed that, with the increasing truck and bus industry in Columbia, local pressure would be applied to the Ministry of Public Works to repair the deep holes which will develop in cheap bituminous pavements if maintenance and retreatment is delayed, and that such pressure would be greater than if a gravel and stone road is allow to deteriorate." [1958, 143] This strategy might be compared in effectiveness to a "conditionality" toward the same end.

${ }^{19}$ He cites Albert Fishlow's study [1965] of the development of American railroads as being piecemial and not ahead of demand-and, one might add, not a component of a master development plan.
} 
the rulers. ${ }^{20}$ In psychological terms, the domestic induced demands for reforms supplies the government with a more "intrinsic" motivation for reform in contrast to the "tough performancebased" carrots and sticks imposed by external development agencies and donors, and in contrast to gifts from benevolent benefactors. In making the reforms, the government is "in the driver's seat" and is "doing its job" of responding to its constituents, not just caving in to foreign pressures. It is not just playing another round in the aid game: "we will pretend to make the reforms so that you can pretend to be doing your job as an aid agency by giving us money."

\section{Other Theories of Decentralized Social Learning and Change}

\section{Herbert Simon's Theory of Bounded Rationality}

One generative metaphor for Herbert Simon's work on bounded rationality is the labyrinth or maze. ${ }^{21}$ We are "in the maze," not "over the maze" surveying all the options from an Olympian perspective. One does not see all the possibilities at any one time, one does not know the probabilities of the outcomes given one's choices, and one does not have the computational capacity to determine an "optimal" outcome even if one had this information. Thus our capacity for "rational" behavior is bounded in many dimensions.

Orthodox economics has, according to Simon, reacted to these limitations by trading one impracticality for another. Instead of assuming knowledge of the outcomes of choice, economics assumes a known probability distribution so that the decision-maker can maximize the expected value of the objective. In contrast, a behavioral theory of bounded rationality [Simon 1955] would have to 'satisfice' rather than maximize. Simon also refers to this as "procedural rationality" in contrast to the "substantive rationality" that only has limited applicability outside of the laboratory experiments and the textbooks. One needs to operate on the basis of heuristics and rules of thumb to prune the tree of possibilities and obtain a decision that is good enough. Complex decisions might also be made more tractable by identifying tangible subgoals or by subdividing the problem into parts that can be handled by experienced decision-makers coordinated through an organizational structure [1979].

While Simon does not directly address the problems of economic development, his work (aside from Austrian economics) has pioneered the critique of the substantively rational decision-maker that is manifested in planning models and, more generally, in the ambitions of technocratic reason. The contrast of being "in the maze" instead of "over the maze" is a useful mental model to use in comparing realistic development strategies with the dreams of comprehensive development planning.

\section{Charles Lindblom's Theory of Incrementalism and Muddling-Through}

Economists such as Jan Tinbergen [1956] tended to view public policy-making as a comprehensive technocratically rational process of surveying the feasible alternatives, evaluating them according to some agreed-upon objective or welfare function, and choosing the most

\footnotetext{
${ }^{20}$ See Powelson and Stock 1987 for case studies of successful reforms "by leverage" from below in contrast to reforms "by grace" from above that eventually failed.

${ }^{21}$ See Simon 1991, Chapter 11 "Mazes Without Minotaurs."
} 
preferred alternative. Charles Lindblom ${ }^{22}$ argued that limited cognitive capabilities, complexity, uncertainty, and conflicting values excluded any such "synoptic" policy-making process. For those reasons, actual policy-making is better described as "disjointed incrementalism" and "muddling through." Moreover he would argue that in most commonly occurring policy environments, sequential decisions are better made in this manner. When exploring a largely unknown environment, it is better to take small steps in the neighborhood of what is known than to take bold leaps into the unknown.

The similarities between Lindblom's process of incremental muddling-through in policy-making and Hirschman's theory of unbalanced growth were so striking that they authored a joint article ${ }^{23}$ pointing out the convergence. Both approaches are skeptical of order, balance, and detailed programming based on foresight, centralized direction, and integrated overviews.

[Both] agree it is most important that arrangements exist through which decision makers are sensitized and react promptly to newly emerging problems, imbalances, and difficulties; this essential ability to react and to improvise readily and imaginatively can be stultified by an undue preoccupation with, and consequent pretense at, advance elimination of these problems and difficulties through 'integrated planning'. [Hirschman and Lindblom 1969, 364]

One of the popular themes today in aid agencies is knowledge-based development assistance conceived of as the agency "giving" or disseminating the solution to a problem to a developing country. Yet Hirschman and Lindblom agree that this will "often result in complicating the problem through mistaken diagnoses and ideologies" and thus they argue that "the much maligned 'hard way' of learning by experiencing the problems at close range may often be the most expeditious and least expensive way to a solution." [364] Where conflict arises, they see the "mutual adjustment" of the participants as achieving a kind of coordination that could not have been anticipated or centrally planned. Similar processes of mutual adjustment without central control are evidenced in the procedures of common law (coordinated by precedents set by different judges), in Michael Polanyi's theory of coordination in science, ${ }^{24}$ and Mary Parker Follett's notion of horizontal coordination by reciprocity in organizations. ${ }^{25}$ Finally, they see in this "political adjustment and strife analogues to self-interested yet socially useful adjustment in the market." [364]

\section{Donald Schön's Theory of Decentralized Social Learning}

Centralized research in a company often faces the problem of translating the results to the core businesses of the organization. Can research "impose" its best ideas on the often reluctant operational units? The operational units might not appreciate the genuine breakthrough embodied in the research, or the research unit might not realize the inapplicability of its pet ideas. The research-operations relationship faces all the problems of the center-periphery relation described by Donald Schön in a context close to the World Bank's work.

\footnotetext{
${ }^{22}$ See Lindblom 1959, 1979, 1990 and Braybrooke and Lindblom 1963.

${ }^{23}$ Hirschman and Lindblom 1969. The article also considered the convergence with the theory of technological research and development of Klein and Meckling 1958.

${ }^{24}$ See Polanyi 1966 p. 217 or 1966 pp. 70-4 in addition to 1951.

25 See Metcalf and Urwick 1942 pp. $297-314$ cited in Lindblom 1965, p. 8.
} 
[The standard approach] treats government as center, the rest of society as periphery. Central has responsibility for the formation of new policy and for its imposition on localities at the periphery. Central attempts to 'train' agencies at the periphery. In spite of the language of experimentation, government-initiated learning tends to be confined to efforts to induce localities to behave in conformity with central policy. Localities learn to beat the system. Government tends to bury failure or learn from it only in the sense of veering away from it. Evaluation, then, tends to be limited to the role of establishing and monitoring the extent of peripheral conformity with central policy. [Schön 1971, 177]

But social learning can take place in a decentralized bottom-up manner with centralized coordination. In large multi-plant companies, innovation may take the form of new ways of socially organizing and structuring productive processes, e.g., quality circles or self-managed work teams. Separate plants might perform pilot experiments to find out "what works and what doesn't." Headquarters frames the experiments, detects the successes, and plays the knowledgebroker to help other plants cross-learn from the successful ones. Schön described a similar process between the government and the periphery of local units trying to carry out a certain social reform.

Government cannot play the role of 'experimenter for the nation', seeking first to identify the correct solution, then to train society at large in its adaptation. The opportunity for learning is primarily in discovered systems at the periphery, not in the nexus of official policies at the center. Central's role is to detect significant shifts at the periphery, to pay explicit attention to the emergence of ideas in good currency, and to derive themes of policy by induction. The movement of learning is as much from periphery to periphery, or periphery to center, as from center to periphery. Central comes to function as facilitator of society's learning, rather than as society's trainer. [Schön 1971, 177-8]

These two models of the center as trainer in the center-periphery model or as the broker/facilitator in the decentralized model are the two very different models for a "Knowledge Bank" (illustrated below in Figure 1). 


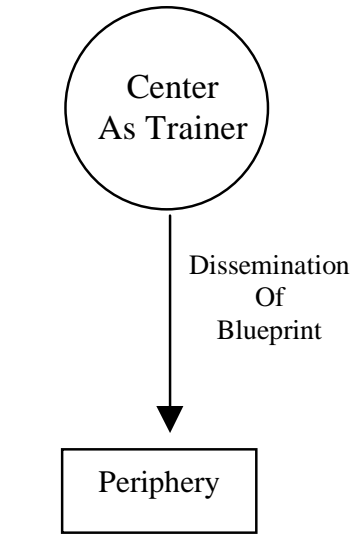
Center-Periphery
Model with
Center as Trainer

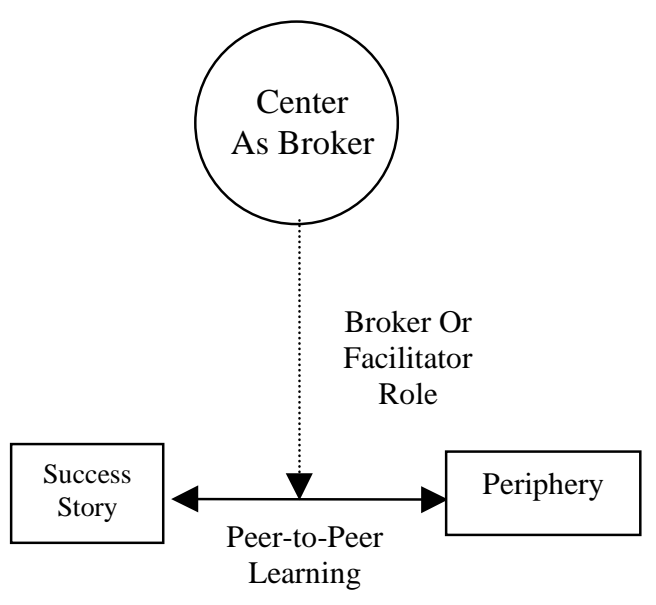

\section{Decentralized Model with Center as Broker}

Figure 1

Social learning is often very different from laboratory learning. Novel complexity, genuine uncertainty, conflict of values, unique circumstances, and structural instabilities mitigate against "laboratory conditions" for discovery and learning. Decentralized experimentation with centrally-sponsored framing and quality benchmarking followed by cross-learning in the periphery ${ }^{26}$ is a more appropriate model than classical "normal science" research at a central facility followed by the teaching-dissemination of the (sometimes impractical) results.

\section{Everett Roger's Theory of Decentralized Innovation and Diffusion}

In Everett Rogers' early work on the diffusion of innovations he focused on the classical huband-spokes or center-periphery model of diffusion.

In this classical diffusion model, an innovation originates from some expert source (often an R\&D organization). This source then diffuses the innovation as a uniform package to potential adopters who accept or reject the innovation. The role of the adopter of the innovation is that of a passive accepter. [Rogers 1983, 333]

Spurred on by Schön's work [1971], he became aware of decentralized diffusion systems with horizontal diffusion between peers (which might involve partial re-invention ${ }^{27}$ of the model) rather than vertical transmission from experts to adopters.

\footnotetext{
26 See CityNet 1998 for a manual on peer-to-peer knowledge transfers and for websites that organize this process using the Internet.

27 "The significance of this point of view is that contrary to the simplistic use of the term by many economists, there is, in principle, no such thing as diffusion of best practice. At best, there is only the diffusion of best practices, practices that evolve in the course of their diffusion. Contrary to popular wisdom, there are times when it pays to reinvent the wheel!" [Cole 1989, 117] "Every alleged example of local implementation of central policy, if it results in significant social transformation, is in fact a process of local social discovery." [Schön 1971, 161]
} 
During the late 1970s I gradually became aware of diffusion systems that did not operate at all like the relatively centralized diffusion systems that I had described in my previous books. Instead of coming out of formal R\&D systems, innovations often bubbled up from the operational levels of a system, with the inventing done by certain users. Then the new ideas spread horizontally via peer networks, with a high degree of re-invention occurring as the innovations are modified by users to fit their particular conditions. ...

Gradually, I began to realize that the centralized diffusion model was not the only wheel in town. [Rogers 1983, 334]

Perhaps the best example of centrally sponsored system of decentralized innovation and diffusion in a developing country is in China over the last quarter of a century. Contrary to the classical model of reform models being established in the center and disseminated to the periphery, the Chinese recognized local reform models which could be in a region, county, commune, or even brigade. The local model could be in any sector or area such as administration, health, education, or industry, and could be visited by groups from all over China who want to make a similar reform in their locality.

The diffusion of innovations in China is distinctive in that it is (1) more horizontal in nature, (2) less dependent upon scientific and technical expertise, and (3) more flexible in allowing re-invention of the innovation as it is implemented by local units. These aspects of decentralized diffusion are facilitated by China's use of such diffusion strategies as models and on-the-spot conferences. The "learning from others" approach to decentralized diffusion in China was adopted officially as a national policy in the national constitution in 1978. [Rogers 1983, 340-1]

The same period marks the beginning of China's historic record of growth and development at the end of the twentieth century.

\section{Just-in-Time Inventory and Continuous Improvement Systems}

The Japanese just-in-time (JIT) inventory system can be looked at as a system of production learning. Buffer inventories in production might be analogized to loans from international development agencies that allow one to get by current difficulties without necessarily solving the underlying problems. But with a JIT system, the costs of the problem are evident and attention is then focused on solving the problem so that it does not recur again. Hirschman has praised the low tolerance for error and narrow latitude of some technical systems (e.g., aircraft maintenance or road surfaces where the low maintenance will show up as destructive potholes) which thus serve as inducement or pacing mechanisms for maintenance and learning. High tolerance for error or wide latitude for maintenance would operate like high inventory levels to weaken the incentives for corrective actions.

Just as a lowering of the water in a canal will reveal obstacles to navigation, so a systematic reduction in the levels of inventories will bring problems to the surface so that this created necessity will be the mother of invention to resolve the problems. Then with a continuous 
reduction in inventory levels, other problems will come to the surface and be resolved in a process of continuous improvement.

This successive removal of inventories creates bottlenecks in production that make it possible to identify each work station's weaknesses; and in this way it is analogous to the potentially informative disruptions of production caused by, say, the construction of a new steel plant in stories of unbalanced growth. [Sabel 1994, 240]

Hirschman has been asked if he would actually advocate "unbalanced growth" in view of the efficiency properties of the formal models of balanced growth (which ignore the dynamics of learning), and one of his responses is that in the JIT inventory system, "the Japanese initiate and induce it." [Hirschman 1994b, 319]

\section{Charles Sabel's Theory of Learning by Monitoring}

Although not explicitly developed as a theory of learning, Hirschman's theory of unbalanced growth can be usefully seen as a theory of decentralized social learning [see Schön 1994] in a manner that will induce decision-making by the "doers of development," will collect and release scattered and dormant local energies, and will instill "ownership" in the learners. The Japanese system of just-in-time inventories, local problem-solving by teams, benchmarking between teams, and continuous improvement can also be seen as a system of systematic learning in production that induces decision-making, problem-solving, and ownership by the participants. Charles Sabel has developed these and other examples in his theory of learning by monitoring [1994].

Often development strategies are flawed by implicitly assuming that which needs to be created. This often takes the form of assuming an effective governance system is in place so that a development advisor simply has to pour some new wine into the sound bottle, e.g., design a comprehensive set of conditionalities to be implemented by a developing country. In large organizations, top managers often adopt new strategic plans as if the problems lay in the specifics of the plan rather than in the lack of capacity to implement management's writ. The implicit assumption of an effective governance system imputes to the government of a country or to the management of a company a capacity to resolve coordination and collective action problems by command and control. Hirschman and Sabel take a different starting point. They ask how collective action problems are solved in the small and how change does take placewithout assuming an effective fiat from the center. By developing a more realistic theory of change, they can then "back out" a more reasonable description of what the center could do to catalyze, assist, broker, and guide the process-rather than trying to finesse the problem by assuming $a b$ initio that the center can effectively implement its plans.

Sabel's treatment of collective action problems through learning by monitoring is particularly fruitful by showing important ways in which trust and "social capital" are developed without falling back on the conventional banalities about cultural inheritance and education. Individuals are assumed to have some sociability, some powers of reflection and discussion, and incomplete identities always in the process of formation and change (incompletely specified preference orderings in economists' terms). They are often in problematic situations where some 
cooperative action would benefit the group but where each may be vulnerable to the noncooperation of others (which could be defection or simply error). The problem being discussed is not a problem involving others in some distant place; it is the group members' own common problem so that they would be involved in implementing any proposed solution (the "learning") and will thereby be monitoring the actions of others-and hence the description "learning by monitoring." The discussion to arrive at a collective action plan must also include discussion of how to apportion the gains from cooperation and how to adjudicate differences that will arise.

So far the description of learning by monitoring does not differ substantially from the repeated games treatment of the evolution of "cooperation" [e.g., Axelrod 1984]. Sabel goes beyond the game-theoretic treatment by assuming that the self-definitions and identities of the participants are changed by the discussion and cooperative efforts. Part of the discussion is to reinterpret and reframe their past, to discover and clarify their interests, and to establish a group identity with which the members can start to identify so that the cooperation is based more and more on "who they are" than on a tenuous game-theoretic modus vivendi (cooperating today only to avoid punishment tomorrow). The reciprocal belief that others also cooperate partly on the basis of identification (rather than strategy and guile) will lead to giving others some "benefit of the doubt" by interpreting occasional non-cooperation by members as error rather than betrayal. In such a manner, trust and the norms of reciprocity (social capital) can be developed.

Central managers or coordinators, instead of being assumed as a deus ex machina, can be seen as agents of the group facilitating the "government by discussion" within the group and helping to minimize the vulnerabilities of cooperative action-while through benchmarking and other means of competitive stimulus helping to insure that the group continues to face the problems that come to light.

Where a set of people have interdependent opportunities and fates, the group members through initial problem-solving discussion and action accompanied by mutual monitoring can start to bootstrap a new collective identity that can help to stabilize future cooperative problem-solving and learning. Overall, this is a species of pragmatism which John Dewey saw as being exemplified in scientific communities and democratic polities.

Learning by monitoring is in this sense an institutional device for turning, amidst the flux of economic life, the pragmatic trick of simultaneously defining a collective-action problem and a collective actor with a natural interest in addressing it. The disequilibria created by learning by monitoring are informatively effective for the same reasons as scientific experiments and democratic rule; and under these conditions the differences between the disciplines of the factory and the laboratory dwindle in the face of their similarities. [Sabel 1994, 272]

\section{Could a Project be a Decentralized Competitive Social Learning Process?}

How might some of these ideas be brought to bear on project design? Start with a persistent social problem in a developing or transitional country, e.g., how to do bankruptcies, industrial restructuring, promoting small private firms in a corrupt environment, and so forth. The Center proposes a contest of subunits (e.g., regions, states, cities, etc.) for the best approach to 
addressing or solving the problem. To qualify, an entrant must make public the "theory" behind their approach (e.g., get the best guru from an elite university or agency, and ask him how to solve the problem, or look at how the problem was addressed in slightly more developed countries, and so forth). Moreover, they must agree to be judged by certain public benchmarking criteria (which they might themselves propose). Based on the proposals, some of which could describe already existing programs, the Center will select a certain number of winners and will provide material assistance in some form, e.g., a block grant. The assistance will always require a substantial matching contribution (which could be as prior investment) from the entrants to assure that they want to solve the problem, not just get the assistance. The losers in the contest will learn the winning theories as to how the problem can be addressed and they may choose to adapt their own mode of operation. After a certain time period, the results are assessed according to the previously agreed-upon benchmarks to see who the real winners were.

There might be a second round of assistance where aid would go to those who did well in the first round (whether they previously received assistance or not). The point is to encourage horizontal or cross-learning between those who did well and those who didn't. Project funds might also be used to sponsor visits or secondments so that the laggards could learn directly from the emerging success stories. The public benchmarking establishes a rolling standard that will ratchet up as social learning improves performance (continuous improvement). Matters of local pride and prestige will play a role.

This type of project starts with a problem, not with a solution. Locally adapted and rooted solutions are found by decentralized experimentation, not imposed from the Center. The Center acts as a sponsor of the decentralized social experiment and acts as a broker to facilitate crosslearning of the laggards from the leaders.

\section{Conclusions}

Many development strategies implicitly assume (or desperately hope) that a country already has a planning and implementation capacity to make institutional reforms from the top down and/or that institutional reforms can be somehow pushed through with the external pressures of aid and conditionalities. In a decentralized reform strategy, developmental transformations are induced not by governmental fiat but by releasing and channeling local energies in smaller projects that will in due course spread by forward and backward linkages as well as through horizontal learning, benchmarking, and imitation.

Although Albert Hirschman developed his strategy of unbalanced growth in response to the postwar theories of the "big push," development planning, and balanced growth, we can triangulate on essentially the same overall strategy from different starting points. The Japanese system of production based on just-in-time inventory, local problem solving, benchmarking, and continuous improvement, Charles Lindblom's theory of incrementalism and muddling through, Donald Schön's and Everett Roger's treatment of decentralized social learning, and Charles Sabel's theory of learning by monitoring are all based on similar ideas. 


\section{References}

Axelrod, Robert 1984. The Evolution of Cooperation. New York: Basic Books.

Braybrooke, David and Charles Lindblom, 1963. The Strategy of Decision. New York: Free Press.

Brehm, Jack 1972. Responses to the Loss of Freedom: A Theory of Psychological Reactance. Morristown NJ: General Learning Press.

Burke, Edmund 1937 (1790). Reflections on the French Revolution. The Harvard Classics: Edmund Burke. C. Eliot. New York: Collier: 143-378.

CityNet 1998. Guidelines for Transferring Effective Practices: A Practical Manual for South-South Cooperation. Available at: http://www.sustainabledevelopment.org/blp

Cole, Robert E. 1989. Strategies for Learning. Berkeley: University of California Press.

Cyert, Richard and James March 1963. Behavioral Theory of the Firm. Englewood Cliffs NJ: Prentice-Hall.

Deci, Edward and Richard Ryan 1985. Intrinsic Motivation and Self-Determination in Human Behavior. New York: Plenum Press.

Ellerman, David 2000a. The Indirect Approach. Washington: World Bank Policy Research WP \#2417.

Ellerman, David 2000b. Helping People Help Themselves: Autonomy-Compatible Assistance. Operations Evaluations Department WP Series No. 7 (Summer 2000). Washington: World Bank.

Fishlow, Albert 1965. American Railroads and the Transformation of Ante-Bellum Economy. Cambridge: Harvard University Press.

Hayek, Friedrich A. 1978. New Studies in Philosophy, Economics and the History of Ideas. Chicago: University of Chicago Press.

Hirschman, Albert O. 1961 (1958). The Strategy of Economic Development. New Haven: Yale University Press.

Hirschman, Albert O. 1971. A Bias for Hope: Essays on Development and Latin America. New Haven: Yale University Press.

Hirschman, Albert O. 1981. A generalized linkage approach to development, with special reference to staples. In: Essays in Trespassing: Economics to Politics and Beyond. Cambridge: Cambridge University Press: 59-97.

Hirschman, Albert O. 1984. A Dissenter's Confession: "The Strategy of Economic Development" Revisited. Pioneers in Development. G. Meier and D. Seers Eds. New York: Oxford University Press: 87-111.

Hirschman, Albert O. 1992. Rival Views of Market Society. Cambridge: Harvard University Press.

Hirschman, Albert O. 1994a. A Propensity to Self-Subversion. Rethinking the Development Experience: Essays Provoked by the Work of Albert O. Hirschman. L. Rodwin and D. Schön. Washington: Brookings Institution: 277-83.

Hirschman, Albert O. 1994b. Hirschman: Responses and Discussion. Rethinking the Development Experience: Essays Provoked by the Work of Albert O. Hirschman. L. Rodwin and D. Schön. Washington: Brookings Institution: 314-21.

Hirschman, Albert O. 1995. A Propensity to Self-Subversion. Cambridge: Harvard University Press.

Hirschman, A. and C. Lindblom 1969. Economic development, research and development, policy making: some converging views. Systems Thinking. F. E. Emery. Harmondsworth: Penguin: 351-71. [Reprint of: 1962. Behavioral Science 7: 211-22.]

Israel, Arturo 1987. Institutional Development: Incentives to Performance. Washington: World Bank.

Killick, Tony with R. Gunatilaka and A. Marr. 1998. Aid and the Political Economy of Policy Change. London: Routledge.

Klein, B. and W. Meckling, 1958. Application of operations research to development decisions. Operations Research 6: 352-63. 
Krugman, Paul 1994. The Fall and Rise of Development Economics. Rethinking the Development Experience: Essays Provoked by the Work of Albert O. Hirschman. L. Rodwin and D. Schon. Washington: Brookings Institution: 39-58.

Lavoie, Don 1985. National Economic Planning: What is Left? Cambridge: Ballinger.

Lavoie, Don 1992. Glasnost and the Knowledge Problem: Rethinking Economic Democracy. Cato Journal 11(3): $435-55$.

Leibenstein, Harvey 1966. Allocative Efficiency versus X-Efficiency. American Economic Review 56(3): 392-415.

Leibenstein, Harvey 1980. Beyond Economic Man: A New Foundation for Microeconomics. Cambridge MA: Harvard University Press.

Lepper, Mark R. and David Greene, Eds. 1978. The Hidden Costs of Rewards: New Perspectives on the Psychology of Human Motivation. Hillsdale NJ: Erlbaum.

Lindblom, Charles 1959. The science of 'muddling through'. Public Administration Review 19: 79-88.

Lindblom, Charles 1965. The Intelligence of Democracy: Decision Making Through Mutual Adjustment. New York: Free Press.

Lindblom, Charles 1979. Still Muddling, Not Yet Through. Public Administration Review 39 (Nov./Dec.).

Lindblom, Charles 1990. Inquiry and Change. New Haven: Yale University Press.

Metcalf, Henry and L. Urwick, Eds. 1942. Dynamic Administration: The Collected Papers of Mary Parker Follett. New York: Harper.

Mosley, Paul, Jane Harrigan, and John Toye. 1991. Aid and Power: The World Bank and Policy-based Lending. Vol. 1. London: Routledge.

North, Douglass 1994. Economic Performance through Time. American Economic Review 84: 359-68.

Perroux, Francois 1953. Note sur la notion de 'pole de croissance'. Economie appliquee 8(Jan.-June): 307-20.

Polanyi, Michael 1951. The Logic of Liberty. Chicago: University of Chicago Press.

Polanyi, Michael 1962. Personal Knowledge: Towards a Post-Critical Philosophy. Chicago: University of Chicago Press.

Polanyi, Michael 1966. The Tacit Dimension. Garden City NY: Doubleday.

Powelson, John and Richard Stock, Eds. 1987. The Peasant Betrayed: Agriculture and Land Reform in the Third World. Boston MA: Lincoln Institute of Land Policy.

Rogers, Everett 1983. Diffusion of Innovations. Third ed. New York: Free Press.

Rosenberg, Nathan 1969. The Direction of Technological Change: Inducement Mechanisms and Focusing Devices. Economic Development and Cultural Change 18(1): 1-24.

Rosenstein-Rodan, Paul 1943. Problems of Industrialization of Eastern and South-Eastern Europe. Economic Journal 53(June-Sept.): 202-11.

Rosenstein-Rodan, Paul Ed. 1964. Capital Formation and Economic Development. Cambridge: MIT Press.

Sabel, Charles 1994. Learning by Monitoring: The Institutions of Economic Development. Rethinking the Development Experience: Essays Provoked by the Work of Albert O. Hirschman. L. Rodwin and D. Schön. Washington: Brookings Institution: 231-74. [Also in: 1994. Handbook of Economic Sociology. N. Smelser and R. Swedberg Eds.. Princeton: Princeton University Press and Russell Sage Foundation: 137-65.]

Schön, Donald 1971. Beyond the Stable State. New York: Norton.

Schön, Donald 1994. Hirschman's Elusive Theory of Social Learning. Rethinking the Development Experience: Essays Provoked by the Work of Albert O. Hirschman. L. Rodwin and D. Schön. Washington: Brookings Institution: 67-95.

Schumacher, E.F. 1997. This I Believe and other Essays. Devon UK: Resurgence Books. 
Sen, Amartya 1999. Development as Freedom. Oxford: Oxford University Press.

Simon, Herbert 1955. A Behavioral Model of Rational Choice. Quarterly Journal of Economics 69(1): 99-118.

Simon, Herbert 1979. Rational Decision Making in Business Organizations. American Economic Review 69(4): $493-$ 513.

Simon, Herbert 1991. Models of My Life. New York: Basic Books.

Solow, Robert 1956. A Contribution to the Theory of Economic Growth. Quarterly Journal of Economics LXX (February): 65-94.

Streeten, Paul 1959. Unbalanced Growth. Oxford Economic Papers XI(June): 167-90.

Tinbergen, Jan, 1956. Economic Policy: Principles and Design. Amsterdam: North-Holland.

World Bank 1998. Assessing Aid: What Works, What Doesn't, and Why. Washington.

von Humboldt, Wilhelm 1963. Humanist Without Portfolio. Marianne Cowan Tr., Detroit: Wayne State University Press. 